
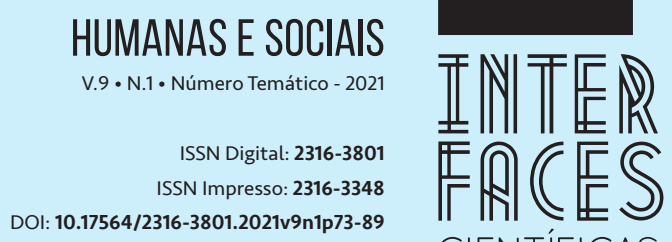

CIENTÍFICAS

\section{OS DESAFIOS E AS PERSPECTIVAS DA INCLUSÃO NOS MUSEUS DE CIÊNCIAS BRASILEIROS}

THE CHALLENGES AND THE PERSPECTIVES OF INCLUSION IN BRAZILIAN SCIENCE MUSEUMS

LOS RETOS Y LAS PERSPECTIVAS DE LA INCLUSIÓN EN LOS MUSEOS DE CIENCIAS BRASILEÑOS

Cláudia Celeste Schuindt ${ }^{1}$ Camila Silveira $^{2}$

NÚMERO TEMÁTICO:

"DEFICIÊNCIA, ACESSIBILIDADE E DIVULGAÇÃO CIENTíFICA"

\section{RESUMO}

O presente estudo busca contribuir para que se ampliem as discussões no tocante à inclusão de pessoas com deficiência nos Museus de Ciências brasileiros e tem como objetivo analisar quais são os desafios e as contribuições dessa prática e sua relação com a acessibilidade. A pesquisa é qualitativa do tipo hermenêutica fenomenológica, buscando compreender determinada realidade e as suas implicações. Como técnica de constituição de dados, foram realizadas entrevistas semiestruturadas com coordenadores/diretores de Museus de Ciências acessíveis de cada uma das cinco regiões geográficas do Brasil e do Guia de Museus e Centros de Ciências Acessíveis. Os dados foram analisados segundo a Análise de Conteúdo e sistematizados em categorias emergentes da análise. Os resultados mostraram que os desafios da inclusão nos espaços museais estão relacionados à dificuldade de acesso inerente às barreiras físicas, arquitetônicas e estruturais; falta de recursos para implementação de medidas de acessibilidade, que influenciam diretamente na inclusão; falta de formação dos mediadores para atender às demandas do público; barreiras comunicacionais; e a pouca participação do público-alvo na formulação de políticas e medidas inclusivas. Ressalta-se que a inclusão rompe com a visão elitizada em relação a essas instituições e promove um cenário de diálogo e pertencimento a todas as pessoas. Apesar das dificuldades, é dever das instituições adotarem medidas que ampliem o acesso e incluam o visitante, haja vista que visitar um museu não significa, apenas, acessar o espaço, mas sim a possibilidade de experimentar e vivenciar o ambiente de forma segura e autônoma.

\section{PALAVRAS-CHAVE}

Inclusão. Museus de Ciências. Educação Museal. Educação Inclusiva. 


\section{ABSTRACT}

This study seeks to contribute for broadening the discussions regarding inclusion of people with disabilities in Science Museums and it aims to analyze what are the challenges and are the contributions of this practice and the relationship with accessibility. The research is qualitative of the phenomenological hermeneutic type that seeks to understand the reality and its implications. As a data constitution technique, a semi-structured interview was conducted with a coordinator/director of the accessible Science Museums from each of the five geographic regions of Brazil and the Guide to Museums and Accessible Science Centers. The data were analyzed according to Content Analysis, systematized in categories emerging from the analysis. The results showed that the challenges of inclusion in museum spaces are related to the difficulty of access, inherent to physical, architectural and structural barriers; lack of resources to implement accessibility measures that directly influence inclusion; lack of training for mediators to meet public demands; communicational barriers and little participation by the target audience in the formulation of policies and inclusion measures. It is emphasized that inclusion breaks with the elite view of these institutions and promotes an environment of dialogue and belonging to all people. Despite the difficulties, it is the duty of the institutions to adopt measures that expand access and include the visitor, owing to visiting a museum does not only mean accessing the space, but rather the possibility of experiencing and experiencing the environment, in a safe and autonomous way.

\section{KEYWORDS}

Inclusion. Science Museums. Museal education. Inclusive education.

\section{RESUMEN}

Este estudio busca contribuir a la ampliación de los debates sobre la inclusión de personas con discapacidad en los museos de ciencias. Con el objetivo de analizar la dificultad, cuáles son las contribuciones a esta práctica y la relación con la accesibilidad. La investigación es cualitativa del tipo hermenéutico fenomenológico que busca entender la realidad y sus implicaciones. Como herramienta recopilada de datos, se realizó una entrevista semiestructurada con un coordinador/director de los Museos de Ciencia Accesible para cada una de las cinco regiones geográficas de Brasil y lo Guía de Museos y Centros de Ciencias Accesibles. Los datos fueron desarrollados de acuerdo con la perspectiva del Análisis de Contenido, sistematizado en categorías que emergen del análisis. Los resultados indicaron que los desafíos de la inclusión en los espacios museísticos están relacionados con la dificultad de acceso, inherente a las barreras físicas, arquitectónicas y estructurales; falta de recursos para implementar medidas de accesibilidad que influyan directamente en la inclusión; falta de capacitación de los mediadores para satisfacer las demandas del público; barreras de comunicación y 
la falta de participación del público objetivo en la formulación de políticas y medidas de inclusión. A pesar de las dificultades, es deber de las instituciones adoptar medidas que amplíen el acceso e incluyan al visitante, ya que visitar un museo no solo significa acceder al espacio, sino la posibilidad de experimentar y experimentar el medio ambiente, de forma segura y autónoma.

\section{PALAVRAS CLAVE}

Inserción. Museos de Ciencia. Educación Museal. Educación Inclusiva.

\section{A INCLUSÃO NOS ESPAÇOS MUSEAIS}

Os Museus de Ciências são importantes espaços de troca e compartilhamento de conhecimento, que contribuem para a comunicação da cultura científica e, consequentemente, para a percepção do papel da Ciência no desenvolvimento científico, tecnológico e social. A divulgação científica busca socializar esse movimento de construção e reconstrução com o público (MOREIRA; MARANDINO, 2015).

Nessa perspectiva, os museus deixam de ser instituições elitizadas e passam a ser espaços de todos e para todos, locais de diálogo que contribuem, do ponto de vista social e educativo, para a ruptura das barreiras nas práticas tradicionalmente estabelecidas, dedicando-se ao desenvolvimento de uma política institucional voltada à inclusão (MARTINS, 2013).

Assim, as práticas museais movimentam-se no sentido da valorização da diversidade, do respeito, do acolhimento e da inclusão, no intuito de que estejam disponíveis para todos os públicos, sem distinções, sem restrições e sem impedimentos. Dessa forma, cabe a cada instituição dedicar-se para desenvolver ações e medidas para a inclusão do público com deficiência de modo a garantir que todos possam interagir, contribuir e se apropriar desses lugares (SARRAF, 2008).

Em vista disso, não é possível falar de inclusão sem percorrer a esfera da acessibilidade, pois estas se interceptam, complementam-se e estabelecem parcerias. Ambas possuem propósitos próprios, que convergem para um objetivo comum: a igualdade de possibilidades e autonomia para todas as pessoas, independente de quaisquer condições (MOLENZANI; NORBERTO ROCHA, 2017). Salasar (2019, p. 13) descreve essa relação como:

Trabalhar com inclusão em ambientes culturais vai além de assegurar que os direitos à cultura sejam garantidos e efetivados; é ampliar espaços de fruição para os mais diversos públicos. E quando se fala em fruição, não é somente estar naquele espaço cultural, mas sim poder expressar-se, participar e produzir novos conhecimentos. Dentro deste contexto, acessibilidade e inclusão são dois conceitos fundamentais, distintos, mas que não podem ser dissociados.

Dentro dessa ótica, a inclusão da pessoa com deficiência em espaços museais é uma demanda que vem se tornando cada vez mais presente nas discussões entre pesquisadores, professores e profissionais da área (MOLENZANI; NORBERTO ROCHA, 2017). Dessa maneira, é fundamental identificar 
como essas pesquisas estão se desenvolvendo, buscando evidenciar quais medidas estão sendo tomadas e como o movimento da inclusão nos espaços museais tem sido entendido.

Celeste e Silveira (2019) buscaram mapear as tendências nas pesquisas acadêmicas que discutem acessibilidade e inclusão em Museus brasileiros, por meio de uma revisão sistemática no Catálogo de Teses de Dissertações da Coordenação de Aperfeiçoamento de Pessoal de Nível Superior (CAPES), seguindo os pressupostos da análise documental. Os resultados do referido estudo mostram que é necessário expandir as estratégias de acessibilidade nas instituições, além de aprofundar a pesquisa na área e promover a consolidação na produção científica nacional.

Segundo Sarraf (2008), as pesquisas se ampliaram a partir dos anos 2000 no nível de especialização (lato sensu) com o Curso de Especialização em Museologia, oferecido pelo Museu de Arqueologia e Etnologia da Universidade de São Paulo, e de 2006, com o Programa de Pós-graduação em Museologia da Universidade Federal do Estado do Rio de Janeiro (stricto sensu).

Entende-se, então, a importância de discutir como a acessibilidade e a inclusão se articulam nos Museus. Mendes Braga (2017) concebe o Museu como promotor da reflexão sobre as narrativas e permite a ampliação do pensamento e da ação. Desse modo, para o autor, a exposição deve superar a cosmovisão dos indivíduos de que os objetos são monumentos que enclausuram a memória, sem se preocupar com quem os produziu em determinado período social e histórico.

Concomitantemente, salienta-se a importância dos Museus de Ciências como espaços inclusivos e acessíveis, como lugares de aprendizagem que, segundo Marques e Marandino (2018), propiciam uma reflexão crítica sobre a narrativa científica exposta, mais lúdica e interativa, uma vez que os conteúdos ali apresentados contribuem para novas experiências, contatos e trocas.

Define-se, dessa maneira, Museus de Ciências acessíveis como sendo espaços que possuem ou sofreram alterações que propiciem a inclusão de todo e qualquer tipo de público, dentre eles, a pessoa com deficiência. Pois, segundo Sarraf (2008, p. 38),

[...] a acessibilidade em museus significa que exposições, espaços de coexistência, serviços de informação, programas de treinamento e todos os outros serviços básicos e especiais oferecidos por Instalações culturais devem estar disponíveis para todos os indivíduos, perceptíveis a todas as formas de comunicação e com seu uso de forma clara, permitindo autonomia dos usuários. Para os museus serem acessíveis, portanto, é necessário que seus serviços sejam adequados para serem alcançados, ativados, usados e vividos por qualquer pessoa, independentemente da sua condição física ou comunicação.

Assim sendo, as adequações podem ser de ordem arquitetônica/física, programática/institucional, comunicacional e/ou atitudinal. Utiliza-se, nesta pesquisa, as definições de medidas acessíveis cunhadas por Schuindt (2019, p. 82) para caracterizar um Museu de Ciências como acessível, apresentadas a seguir:

a) Acessibilidade arquitetônica/física: observou-se nesta categoria os aspectos que abrangem a acessibilidade física local e do entorno da instituição, isto é, desde a chegada do público ao local até a sua recepção e acomodação. 
b) Acessibilidade programática/institucional: observamos quais políticas e medidas os coordenadores/diretores estão buscando implantar para eliminar barreiras para a promoção da acessibilidade.

c) Acessibilidade comunicacional: essa categoria foi observada através da existência/ inexistência de equipamentos e recursos que permitam a superação das barreiras comunicacionais, de escrita e/ou de informação, através da utilização de leitores de tela; tamanho da fonte; alternativas de idioma, por exemplo, Libras ou Braille; recursos táteis de apoio bi e/ou tridimensionais, recursos multissensoriais.

d) Acessibilidade atitudinal: nesta categoria foram observadas as atitudes e ações de formação voltadas para eliminar os preconceitos, estereótipos e estigmas existentes entre as pessoas, tanto pelos funcionários quanto pelos visitantes, como também promover a inclusão profissional da pessoa com deficiência e parcerias com instituições e/ou organizações dirigidas à pessoa com deficiência.

Busca-se, então, uma sociedade inclusiva, em todos os sentidos, com uso de recursos que visem incluir e não simplesmente inserir a pessoa nos ambientes destinados à sua educação, saúde, lazer e trabalho. Nesse sentido, "incluir implica em acolher a todos os membros de um dado grupo, independentemente de suas peculiaridades; é considerar que as pessoas são seres únicos, diferentes uns dos outros e, portanto, sem condições de serem categorizados” (CARDINALI, 2008, p. 76).

Incluir significa acolher, respeitar e, acima de tudo, afastar-se de uma postura assistencialista, afinal, são as singularidades que nos constituem como indivíduos únicos. Dessa forma, para que um espaço seja inclusivo, ele deve proporcionar que o maior número de pessoas, independentemente de suas condições, possa desfrutar das experiências ali apresentadas (SALASAR, 2019).

Porém, para que isso aconteça, é necessário que o ambiente possua recursos para que a pessoa com deficiência possa ter as mesmas possibilidades dos demais visitantes. Define-se, então, os conceitos de acessibilidade e de acesso como sendo a adaptação e reestruturação de ambientes, espaços arquitetônicos, pavimentos, dentre outros, possibilitando o ingresso e a permanência, de maneira segura e autônoma, respeitando os preceitos do desenho universal (ABNT, 2015). Ressalta-se, porém, que nem todos os ambientes acessíveis são inclusivos.

Quando os recursos de acessibilidade são oferecidos separadamente, ou são de uso exclusivo da pessoa com deficiência, descaracteriza-se a inclusão, pois esta pressupõe que a pessoa com deficiência não seja segregada, ou seja, que não tenha disponibilizados os recursos de acessibilidade somente para esse público-alvo (TOJAL, 2015). Segundo a autora,

[...] exemplo disso é o mau hábito de dotar as exposições de recursos de acessibilidade que, isolados de um contexto mais abrangente, pouco ou nada contribuem para o acesso e a compreensão de públicos com deficiência, como etiquetas em Braille fixadas ao lado de obras de arte ou de vitrines expositivas, sem que esses objetos possam ser alcançados e reconhecidos por meio da exploração tátil ou áudio-guias que apenas informam e descrevem os espaços e os objetos, sem que o visitante com deficiência visual possa usufruir sensorialmente de nenhum objeto ou conteúdo da exposição. Assim também textos e in- 
formações difíceis de serem lidos e compreendidos pelos públicos e que, ao invés de estimularem a curiosidade e a experiência concreta, afastam ou desestimulam os públicos a se apropriarem efetivamente desses espaços. (TOJAL, 2015, p. 199).

Portanto, incluir permite entender as potencialidades dos visitantes frente às suas diversidades e disponibilizar os recursos para todos os públicos em um mesmo espaço, visto que a inclusão e a acessibilidade têm o potencial de beneficiar todas as pessoas, cativando-as e tornando-as públicos usuais desses espaços (SARRAF, 2008). 0 respeito às diferenças e a igualdade de oportunidades requerem o movimento de incluir, que rompe com o movimento da exclusão. Diante disso, busca-se, com esta pesquisa, identificar quais são os desafios da inclusão do público com deficiência nos Museus de Ciências acessíveis no Brasil e quais as contribuições dessa prática.

\section{CAMINHOS METODOLÓGICOS}

O presente trabalho é um recorte de uma pesquisa de Mestrado em Ensino de Ciências, cujo projeto foi aprovado pelo Comitê de Ética em Pesquisa em Seres Humanos sob o parecer do CEP/SD - PB n 2.958.426.

Esta pesquisa busca, por meio dos dados construídos, identificar se e como a inclusão da pessoa com deficiência vem sendo desenvolvida nos Museus de Ciências Acessíveis (MCA) do Brasil, bem como analisá-la a partir das relações estabelecidas entre inclusão e acessibilidade com base nas pesquisas realizadas por Tojal (2015), Sarraf (2008) e Salasar (2019). O estudo foi desenvolvido na perspectiva qualitativa da hermenêutica fenomenológica (DITTRICH; LEOPARDI, 2015) e se propôs a delinear e compreender a maneira como os Museus de Ciências brasileiros vêm se apropriando das medidas de acessibilidade como estratégia de inclusão, tendo como ponto de partida a realidade social dos sujeitos e das instituições, buscando compreender o que elas significam para os indivíduos, bem como quais implicações elas trazem.

Os participantes desta pesquisa foram selecionados tendo como referência o Guia de Museus e Centro de Ciências Acessíveis da América Latina e Caribe (NORBERTO ROCHA et al., 2017) e um dos coordenadores/elaboradores do Guia, a fim de entender como o processo de inclusão foi percebido durante sua constituição. Optou-se por esse critério de seleção, pois o Guia traz um levantamento dos dados a respeito da inclusão e acessibilidade nos Museus de Ciências. O referido documento lista 69 instituições museais acessíveis que divulgam ciência e tecnologia no Brasil, bem como os itens de acessibilidade disponíveis e os contatos dessas instituições.

Os dados foram construídos por meio de uma entrevista semiestruturada, contendo questões sobre formação dos entrevistados, tempo na instituição, inclusão, participação da pessoa com deficiência nesse processo, frequência de visitas da pessoa com deficiência, mediação, como as medidas de acessibilidade se articulam com a inclusão, qual a contribuição para a Educação Inclusiva e experiências de inclusão no espaço museal, visando ao delineamento das práticas desenvolvidas pelos MCA.

Para a escolha das instituições participantes foram atribuídos estes critérios: uma instituição por região do Brasil, com sede fixa, ou seja, não itinerante, com a maior quantidade de características 
acessíveis e suas exposições deviam abranger mais áreas do conhecimento, a fim de que fosse selecionada uma por região do país. A busca dessas informações se deu nos sítios da internet e no Guia.

Os dados das instituições selecionadas e dos participantes foram sistematizados no Quadro 1, apresentado a seguir.

Quadro 1 - Descrição dos espaços museais e participantes entrevistados

\begin{tabular}{|c|c|c|}
\hline INSTITUIÇÃO & CARACTERÍSTICAS & $\begin{array}{l}\text { PARTICIPANTES } \\
\text { (PSEUDÔNIMOS) }\end{array}$ \\
\hline $\begin{array}{l}\text { CASA DE CIÊNCIA E } \\
\text { CULTURA DE CAMPO } \\
\text { GRANDE (Centro-Oeste) }\end{array}$ & $\begin{array}{l}\text { Acessibilidade no entorno; } \\
\text { Acessibilidade física; } \\
\text { Materiais que podem ser manipulados; } \\
\text { Áudio-descrição em português. }\end{array}$ & lasmin \\
\hline $\begin{array}{l}\text { LABORATÓRIO DE } \\
\text { DIVULGAÇÃO CIENTÍFICA } \\
\text { ILHA DA CIÊNCIA } \\
\text { (Nordeste) }\end{array}$ & $\begin{array}{c}\text { Acessibilidade física e no entorno; } \\
\text { Alguns materiais manipuláveis; } \\
\text { Computadores com softwares sintetizadores de voz; } \\
\text { Guia vidente e intérprete de Libras; } \\
\text { Materiais que possuem tradução em Libras. }\end{array}$ & Osvaldo \\
\hline $\begin{array}{l}\text { CENTRO DE CIÊNCIAS E } \\
\text { PLANETÁRIO DO PARÁ } \\
\text { (Norte) }\end{array}$ & $\begin{array}{c}\text { Acessibilidade física; } \\
\text { Áudio-descrição em português; } \\
\text { Experimentos manipuláveis; } \\
\text { Guia vidente disponível durante todo o horário de } \\
\text { funcionamento. }\end{array}$ & Silmara \\
\hline $\begin{array}{l}\text { CENTRO DE DIVULGAÇÃO } \\
\text { CIENTÍFICA E CULTURAL } \\
\text { (CDCC) (Sudeste) }\end{array}$ & $\begin{array}{c}\text { Acessibilidade física e no entorno; } \\
\text { Alguns materiais manipuláveis; } \\
\text { Computadores com softwares sintetizadores de voz; } \\
\text { Materiais e roteiros adaptados para pessoas com } \\
\text { deficiência intelectual. }\end{array}$ & Andreia \\
\hline $\begin{array}{l}\text { MUSEU DINÂMICO } \\
\text { INTERDISCIPLINAR (Sul) }\end{array}$ & $\begin{array}{l}\text { Acessibilidade física; } \\
\text { Áudio-descrição em português; } \\
\text { Exposições em Braille; } \\
\text { Materiais manipuláveis. }\end{array}$ & Amanda \\
\hline $\begin{array}{l}\text { GRUPO MUSEUS E } \\
\text { CENTROS DE CIÊNCIAS } \\
\text { ACESSÍVEIS (Guia) }\end{array}$ & $\begin{array}{c}110 \text { espaços científico-culturais; } \\
\text { Argentina, Bolívia, Brasil, Chile, Colômbia, México, } \\
\text { Nicarágua, Panamá, Porto Rico e Uruguai; } \\
\text { Questionário autodeclarado. }\end{array}$ & Júlia \\
\hline
\end{tabular}

Fonte: As autoras (2020). 
A reunião dos dados foi tratada mediante a Análise de Conteúdo (BARDIN, 2016). Esse método implica um conjunto de técnicas de análise e utiliza procedimentos sistemáticos e objetivos de descrição do conteúdo das mensagens. As respostas foram categorizadas a fim de responderem ao objetivo dessa investigação. Posteriormente, foi possível analisar os desafios da inclusão do público com deficiência nos espaços museais e quais as contribuições dessa prática, por meio das novas categorias que emergiram da análise, sejam elas: acessibilidade física, falta de recursos, formação de mediadores, barreiras comunicacionais e participação do público-alvo, que serão discutidas a seguir.

\section{RESULTADOS E DISCUSSÃO}

A análise dos dados se deu segundo os princípios da Análise de Conteúdo, em que foram criadas categorias emergentes à análise a partir de unidades de contexto com a intenção de delinear os desafios da inclusão do público com deficiência nos Museus de Ciências e como a inclusão e a acessibilidade se interrelacionam.

Segundo Tojal (2015, p. 192), o aumento da procura aos Museus de Ciências pelo público com deficiência se deu após um processo longo e delicado de abertura e adequação dessas instituições que eram "inicialmente dedicadas a uma finalidade mais restrita e elitizada", passam a ser alvo de diferentes classes e público variado, o que lhes confere um papel incisivo na transformação do conhecimento científico e na ruptura do paradigma de que o espaço museal se restringe ao invés de se ampliar.

A partir da análise das entrevistas, verificou-se que uma das dificuldades por parte dos espaços museais em incluir a pessoa com deficiência está relacionada à categoria acessibilidade física, ou seja, falta de adequação física e estrutural dos prédios, o que, por vezes, impossibilita o acesso do público com deficiência. Sarraf (2008) aponta que as edificações e os mobiliários devem permitir a utilização e permanência de maneira autônoma, independente e segura, devem ultrapassar os limites da instituição, tornando-se características do ambiente e da sociedade como um todo.

Durante as entrevistas, constatou-se que os Museus, em suma, são parcialmente adaptados e não dispõem de uma estrutura adequada para receber o visitante, conforme o excerto a seguir:

Bom, era pra ter uma rampa de acesso, né? Pra cadeirante (sic) que não... não foi feita, então o... o acesso é assim, é parcialmente adequado porque a pessoa tem que... se vier, né? Se chegar de carro ótimo, tem as rampas tudo, né? Mas se não, se chegar de ônibus, por exemplo, aí ela tem que passar pelo asfalto e tal, não é... como eu disse, é parcialmente acessível, né? (IASMIN).

Ao contrário do que pode ser observado no Guia (NORBERTO ROCHA et al., 2017) quanto à acessibilidade física, a fala da entrevistada retrata que a realidade observada nos Museus nem sempre corresponde ao que é observado na prática. Dentre os entrevistados, apenas o Laboratório de Divulgação Científica Ilha da Ciência possui todos os itens listados no Guia (NORBERTO ROCHA et al., 2017) nos itens de acessibilidade física. Os demais, apesar de indicarem a presença dos itens, ainda não os possuem ou estão em fase de implantação. 
Apesar das leis que regulamentam a inclusão e a acessibilidade nesses espaços, percebe-se que as ações ainda são pontuais e não atendem às demandas do público visitante. Assim, ressalta-se a importância de os Museus serem espaços de discussão e pertencimento de toda a sociedade, independentemente de qualquer condição.

Segundo Sarraf (2008), a diversificação do público tornou-se uma realidade eminente, principalmente pela necessidade de acolher o visitante sem renunciar a suas características, ao incentivar práticas culturais inclusivas e impulsionar a inserção de pessoas que permaneceram segregadas desses espaços por tanto tempo.

Os espaços museais ainda possuem muitas barreiras físicas e arquitetônicas e, em suma, elas prejudicam o acesso às instituições, pois impossibilitam que as pessoas com dificuldade de locomoção acessem os ambientes. Isso fica claro na fala a seguir:

O acesso da pessoa com deficiência... a cúpula, ela não foi originalmente projetada pra isso, né? Então, geralmente, quando vinha alguém, não tem um lugar específico, por exemplo, pra encaixar a cadeira do cadeirante (sic), né? Então, ele fica meio que ali onde seria o caminho, que quando fecha a sala deixa de ser, mas é uma coisa, assim, improvisada. (SILMARA).

Além de impedirem a circulação, as barreiras arquitetônicas podem causar desconforto e constrangimentos. É importante, portanto, que o espaço seja capaz de abrigar e reproduzir várias formas de experiência, possibilitando a identificação das pessoas com os lugares, além de possuir um Plano Museológico que apresente as metas que o museu se propõe implementar, sem distinção de ser ou não voltado à pessoa com deficiência (SALASAR, 2019).

Corroborando, "Não basta só que o museu seja acessível, a cidade tem que ser acessível, os hotéis têm que ser acessíveis, o transporte tem que ser acessível” (JÚLIA).

Além das barreiras físicas, a falta de recursos é um dos fatores apontados pelos gestores das instituições, constitui a segunda categoria e pode ser observado na fala de uma entrevistada: "Mas como é que eu vou fazer? Se eu tenho um vazamento, por exemplo, eu conserto aquilo ou faço uma rampa pra tornar a entrada acessível, entende? Falta recurso e não dá pra fazer tudo” (IASMIM).

O Plano Nacional Setorial de Museus (BRASIL, 2010) estabelece como diretriz prioritária que haja recursos financeiros para que os Museus realizem as adequações necessárias para que os espaços se tornem acessíveis. Entretanto, essa não é a realidade observada, como constatado na fala da coordenadora. Isso é recorrente nas falas dos entrevistados, ou seja, não é uma situação pontual e condiz com o apresentado a seguir: "Então, nós já investimos nessa área, quando nós construímos o museu. Foi o que nós fizemos dentro das condições financeiras que a gente tinha, né? Então, foi... o que deu pra fazer, nós fizemos" (ANDREIA).

É preciso garantir que as adaptações sejam viáveis financeiramente para que os espaços museais possam ser não somente acessíveis como também inclusivos.

Nas falas, verifica-se que apenas o Museu Dinâmico Interdisciplinar tem driblado a falta de recursos com a utilização de materiais de baixo custo para realizar a mediação e até a criação de novas exposi- 
ções, mesmo diante de um cenário financeiramente inacessível. 0 referido Museu tem desenvolvido estratégias para articular as políticas internas e orçamentos para que as medidas de acessibilidade possam entrar em vigor conforme previsto nas leis.

Entretanto, essa não é uma prática observada nos demais museus, que por vezes não possuem fundos para que as adequações sejam realizadas. Dessa maneira, são necessárias medidas complementares pautadas em ações tangíveis, de fácil manutenção para que as peças possam estar, efetivamente, disponíveis para todos os visitantes (TOJAL, 2015).

O público é heterogêneo e, então, além da falta de recursos para implantar medidas de acessibilidade que possibilitam a inclusão, os Museus precisam promover a formação dos mediadores para que estes possam atender o público com deficiência adequadamente. Nas falas é possível identificar essa categoria:

A gente tá tentando fazer com que ocorra uma maior qualificação, a gente tem cada... cada início de ano, início de semestre a gente tem capacitações dos ambientes, inclusive Libras e o falar ao público, né? Como se portar com os diferentes tipos de públicos estão entre essas capacitações. (AMANDA).

Para a realização de uma mediação cultural inclusiva nos espaços museais, Sarraf (2008) indica que é preciso interpretá-la para além da relação interpessoal, não se restringindo à presença física do educador junto ao visitante e sim à ação com os elementos mediadores. Tojal (2015) salienta que as políticas institucionais precisam estabelecer ações de articulação e potencialização a fim de promoverem a acessibilidade de maneira integrada, tanto aos Museus quanto aos profissionais.

O Laboratório de Divulgação Científica Ilha da Ciência, o Centro de Ciências e Planetário do Pará possuem guias preparados para atender o público com deficiência durante as visitas, o que está de acordo com as informações declaradas no Guia (NORBERTO ROCHA et al., 2017); o Museu Dinâmico Interdisciplinar, apesar de não declarar essa possibilidade, possui mediadores para atuarem no atendimento da pessoa com deficiência.

Os demais não possuem e não informaram estabelecer parcerias com instituições para esse tipo de atendimento. Destaca-se a importância de que esses profissionais sejam familiarizados com o museu, assim como com a inclusão, para que a mediação não seja apenas descritiva, mas envolva o visitante e possibilite que as interações ocorram de maneira igualitária, respeitando a diversidade do público.

Porém, nem sempre o processo de formação dos mediadores supre as necessidades reais do espaço museal, como fica claro em: "Mas os monitores, eles são treinados, recebem um treinamento, mas não é tão aprofundado" (ANDREIA).

A formação continuada dos monitores reflete a necessidade de aperfeiçoamento e a preocupação por parte dos gestores em superar os obstáculos da inclusão que, concordando com Norberto Rocha e Marandino (2017), são, justamente, a falta de preparo dos profissionais no campo museológico.

Além da formação dos profissionais, uma das preocupações crescentes dentre os entrevistados inclui as barreiras comunicacionais de escrita e/ou de informação, por meio das alternativas de idioma, por exemplo, Libras ou Braille, adaptação das exposições, criação de materiais táteis, manipuláveis e multissensoriais, o que caracteriza a quarta categoria. 
A comunicação é uma necessidade básica e deve ser atendida nos espaços museais, assim como nas demais esferas da sociedade. A acessibilidade comunicacional envolve toda forma de comunicação concebida para o espaço expositivo, incluindo a seleção dos objetos, textos, etiquetas, montagem e iluminação (TOJAL, 2015). Entretanto, a fala da entrevistada aponta que a preocupação em criar exposições com novas linguagens é recente:

Então, a gente não tinha essa tradição até agora, a gente..., mas a gente... a gente agora tá com a perspectiva de... de a partir de agora fazer todas as nossas exposições com um... com essa preocupação, né? E aí a gente tá começando com isso agora. Então são as constelações táteis que servem tanto pra cegos quanto pra espectro autista, pessoas com deficiência cerebral, né? Porque você concretiza, né? Então o deficiente visual pode tatear e ver qual é o tamanho dos planetas, né? Vê com as mãos qual é o tamanho dos planetas, os anéis de saturno. Esse tipo de coisa. Então quem enxerga ou quem não enxerga vai poder tocar, vai, né? (IASMIM).

Para Salasar (2019), os Museus são ambientes essencialmente comunicativos, que buscam, por meio do acervo, dialogar com seus visitantes, utilizando, principalmente, os demais outros sentidos do visitante, ou seja, a audição, o tato e a visão. Dessa maneira, faz-se necessário analisar se o ambiente está favorecendo a aprendizagem com a oferta de recursos audiovisuais e multissensoriais, além da eliminação de barreiras arquitetônicas.

Os Museus de Ciências estão se adaptando à realidade da inclusão da pessoa com deficiência, preparando materiais e adequando as exposições, entretanto, essas mudanças envolvem mais do que sujeitos, objetos e conhecimentos; é preciso que as exposições sejam configuradas de maneira adequada para que os educadores e os visitantes possam interagir durante a visita (SARRAF, 2008). Observa-se que

Nas nossas exposições... nas nossas exposições a gente faz uma leitura de diferentes experimentos, tá certo? Pra que as pessoas possam perceber. Por exemplo, você faz experimento de quente e frio mostrando a lei da termodinâmica, né? Você... a gente faz alguns modelos em 3D porque temos também o centro de astronomia mostrando os planetas, os satélites, levando eles, né? [...] Todos eles são identificados em Braille. (OSVALDO).

Entretanto, é possível constatar que essa proposta não está disponível para todas as exposições e nem para todos os públicos, o que vai contra as informações presentes no Guia (NORBERTO ROCHA et al., 2017). Os museus têm muita dificuldade em realizar adaptações comunicacionais para que 0 público com deficiência seja incluído. Entre os museus analisados, nenhum deles já possui, efetivamente, o que declara no questionário, portanto as informações não condizem com a realidade, bem como nem todos os espaços museais sentem-se preparados para colocá-las em prática ou já desenvolveram metodologias alternativas para romper com essa barreira:

Principalmente as... assim, inclusão assim, por exemplo, uma pessoa com inclusão de visão, fica assim, fica meio complicado, né? Por exemplo, você... uma máquina térmica, né? Ele não pode ter acesso, ele não pode tocar, ele não pode tocar não só com as mãos, também 
com o olhar, ele não pode olhar. Então você tem que dar uma linguagem especial pra essa pessoa, dar um atendimento especial, tá certo? E observação de luz, né? Como? Então como mostrar, né? Observação de luz, entendeu? Então nós temos dificuldades e certas dificuldades, né? Tanto na parte de ótica como na parte de termodinâmica, né? (OSVALDO).

Tojal (2015) afirma que a acessibilidade comunicacional está diretamente ligada à acessibilidade atitudinal. A autora enfatiza que é necessário pensar nos processos de comunicação museológica que privilegiem as formas de mediação a fim de efetivamente promover a autonomia da pessoa com deficiência. Assim,

Nenhum recurso técnico voltado para a satisfação de exigências de acessibilidade efetivamente logrará êxito se desacompanhado de uma acessibilidade comunicacional e atitudinal previamente desenvolvidas, que permitam orientar o manejo desses mesmos recursos, viabilizando uma implantação efetiva e, por conseguinte, eficaz. (TOJAL, 2015, p. 191).

Segundo a autora, as medidas de acessibilidade não devem ser oferecidas de maneira isolada. É certo que a percepção humana se dá por meio da combinação de estímulos e das sensações por eles produzidas, porém, mais que a soma dessas sensações, é necessário levar em conta que nem sempre os recursos disponíveis alcançarão seu propósito se não planejados em conjunto com a pessoa com deficiência. Dessa maneira, é necessário que o público-alvo atue no planejamento e na implementação dessas ações. Os entrevistados foram questionados quanto a esse movimento de inclusão e identificou-se que essa não é uma prática observada nos espaços museais, como, por exemplo, em:

Atualmente não. Já tivemos, já tivemos e, na verdade, nessa época, a gente... nós tivemos problemas sim, porque o prédio nessa época não tinha, por exemplo, nenhum elevador... Então, ela acabou se transferindo pra um outro lugar, não que ela não desse conta, mas assim, ela preferiu mudar, acho que ela se sentia melhor. Pra um lugar mais adaptado pra ela, tá? Hoje, nós não temos, não, ninguém. (ANDREIA).

Destaca-se que as medidas de inclusão devem ter a participação do público a que se destinam, porém, as exposições e mediações, segundo o observado nas entrevistas, ainda não são pensadas, aplicadas e testadas por pessoas com deficiência, o que distancia e impossibilita o diálogo e a melhor estruturação das ações acessíveis no espaço museal, que por definição deve ser um lugar para todas as pessoas, independentemente de suas necessidades físicas, comunicacionais, intelectuais, dentre outras. 0 único respondente que, atualmente, realiza essa parceria é o Grupo de Museus e Centro de Ciências Acessíveis e salienta a necessidade de a pessoa com deficiência estar envolvida nesse processo:

$\mathrm{Na}$ elaboração do guia sim, teve o Fabiano², que foi o consultor, ele é cego. E ele nos ajudou com a áudio-descrição de todas as imagens, desde a capa até a marca do nosso

2 Pseudônimo adotado para preservar a identidade. 
grupo, as ilustrações da página. Então, quando tinha problemas, por exemplo, problemas muito básicos, mas que a gente... a gente teve um designer que fez a produção do guia, que o designer também nunca tinha produzido um material acessível, o Fabiano foi um dos que fez essa validação, vamos dizer assim, então, foi e voltou várias vezes do designer pra ele. (JÚLIA).

A inclusão transpassa aspectos organizacionais, estruturais e políticos, portanto, é necessário que essas pessoas sejam incluídas desde o processo de planejamento e implementação dessas adaptações e mudanças nos Museus de Ciências, visto que a percepção de atitudes e melhorias devem partir do seu público-alvo. Os recursos de acessibilidade e as atividades de inclusão nos espaços museais beneficiariam a todos os visitantes, não somente a pessoas com deficiência, assim como também apoia Sarraf (2008).

A inclusão envolve um processo de reforma, não somente das estruturas e sistemas, mas de comportamento. É necessário incorporar as modificações no conteúdo, nos métodos, nas abordagens, nas estratégias de educação para superar barreiras, buscando oferecer a todos uma experiência e um ambiente de aprendizado igualitário e participativo, que corresponde às suas demandas. Inserir a pessoa com deficiência em espaços sem esses aprimoramentos e modificações não constitui inclusão (CARDINALI, 2008).

As práticas inclusivas garantem a todos o direito de participar das mais variadas esferas sociais e educativas, um local em que seja possível o acesso e a permanência de todas as pessoas, onde os mecanismos de seleção e discriminação sejam substituídos por procedimentos de identificação e remoção de barreiras, não somente arquitetônicas, mas de aprendizagem, tornando os Museus um espaço de pertencimento, como pode ser visto no depoimento a seguir:

De acolhimento e de pertencimento, "eu posso vir aqui”, né? “Aqui eu vou ser recebido, aqui pode não estar tudo disponível pra mim, mas tem bastante coisa que eu posso observar, que eu posso ter contato, que eu posso aprender". (SILMARA).

Mais do que a missão das instituições, a inclusão desperta o sentimento de respeito ao próximo, estimulando práticas e ações educativas que são benéficas para todos, o que enriquece ainda mais a aprendizagem nos Museus de Ciências e promove experiências marcantes para todos os envolvidos.

As práticas museais devem valorizar a diversidade, estimular o respeito pelas diferenças e acolher. O conhecimento e a fruição presentes nos Museus, espaços científico-culturais e ações de divulgação científica devem contemplar todas as audiências, sem distinções. Nesse cenário, ressaltamos que a acessibilidade se apresenta como aliada da inclusão. Ambas não se restringem à exclusão de barreiras estruturais, mas sim ao movimento de ruptura de certos paradigmas da sociedade, que vão além das condições físicas do sujeito, preconizam a vivência, a participação, a igualdade e a autonomia, o que não acontece somente com a eliminação de obstáculos, mas sim com a criação de novos elos.

Assim, faz-se necessário traçar um estudo efetivo sobre as possibilidades de receber cada pessoa, para tal, medidas e estratégias devem ser planejadas e colocadas em prática no cotidiano do espaço museal para garantir o direito de todos, possibilitando uma nova forma de pensar e agir. 


\section{CONSIDERAÇÕES FINAIS}

No tocante ao exposto, buscamos estabelecer e relacionar as conclusões acerca da pesquisa realizada e sugerir caminhos para futuros trabalhos, não com o intuito de saná-las, mas na perspectiva de expandi-las, de ampliá-las.

Segundo a fundamentação teórica apresentada e a análise das entrevistas realizadas foi possível identificar os desafios da inclusão do público com deficiência nos espaços museais como: i) a dificuldade de acesso relacionada a barreiras físicas, arquitetônicas e estruturais; ii) falta de recursos para implementação de medidas de acessibilidade que influenciam diretamente na inclusão; iii) a falta de formação dos mediadores para atender às demandas do público com deficiência; iv) as barreiras comunicacionais das exposições, muitas vezes atreladas ao manuseio e descrição das peças expostas; e v) o baixo índice de participação do público com deficiência na formulação de políticas e medidas de inclusão no espaço museal.

No que se refere às contribuições dessa prática, o movimento de inclusão da pessoa com deficiência nos Museus de Ciências é, ainda, um processo novo, porém irreversível e rompe com a visão elitizada dessas instituições. Apesar das dificuldades, as instituições têm se adequado, tanto para atender às leis que regulamentam essa prática quanto por passarem por reformas sociais que valorizam a igualdade e a diferença.

Salientamos que é dever das instituições adotarem medidas que visem ampliar o acesso e incluir o visitante, haja vista que visitar um museu não significa, apenas, acessar o espaço. 0 museu deve permitir a todas as pessoas a possibilidade de experimentar e vivenciar o ambiente, de forma segura e autônoma, de modo que possam estabelecer uma relação afetiva com o que está sendo exposto.

\section{AGRADECIMENTOS}

O presente trabalho foi realizado com apoio da Coordenação de Aperfeiçoamento de Pessoal de Nível Superior - Brasil (CAPES) - Código de Financiamento 001.

\section{REFERÊNCIAS}

ABNT - Associação Brasileira de Normas Técnicas. NBR 9050: acessibilidade a edificações, mobiliário, espaços e equipamentos urbanos. Rio de Janeiro, 2015.

BARDIN, L. Análise de conteúdo. 3. ed. Lisboa: Edições 70, 2016.

BRASIL. Ministério da Cultura. Instituto Brasileiro de Museus. Plano Nacional Setorial de

Museus - 2010/2020. Ministério da Cultura: Brasília, 2010. 
CARDINALI, S. M. M. 0 ensino e aprendizagem da célula em modelos táteis para alunos cegos em espaços de educação formal e não formal. 2008. 109 f. Dissertação (Mestrado em Ensino de Biologia) - Programa de Pós-graduação em Ensino de Ciências e Matemática, Pontifícia Universidade Católica de Minas Gerais, Minas Gerais, 2008.

CELESTE, C.; SILVEIRA, C. Acessibilidade nos Museus brasileiros: tendências da produção acadêmica. Museologia \& Interdisciplinaridade, v. 8, n. 16, p. 196-212, 2019.

DITTRICH, M. G.; LEOPARDI, M. T. Hermenêutica fenomenológica: um método de compreensão das vivências com pessoas. Discursos fotográficos, Londrina, v. 11, n. 18, p. 97-117, jan./jun. 2015.

MARQUES, A. C. T. L.; MARANDINO, M. Alfabetização científica, criança e espaços de educação não formal: diálogos possíveis. Educação e Pesquisa, São Paulo, v. 44, p. 1-19, 2018. Disponível em: https://www.scielo.br/scielo.php?pid=S1517-97022017005016102\&script=sci_arttext\&tlng=pt. Acesso em: 1 jul. 2020.

MARTINS, P. R. A inclusão social tem influência nas práticas museais? 0 acesso dos públicos com deficiência. Midas, Portugal, v. 1, n. 2, p. 1-14, abr. 2013.

MENDES BRAGA, J. Desafios e perspectivas para educação museal. Museologia \& Interdisciplinaridade, Brasília, v. 6, n. 12, p. 55-64, set. 2017.

MOLENZANI, A. O.; NORBERTO ROCHA, J. Acessibilidade nos museus e centros de ciências da cidade de São Paulo. Revista do Encontro de Divulgação de Ciência e Cultura, Campinas, v. 3, n. 3, p. 71-83, abr. 2017.

MOREIRA. M. L.; MARANDINO, M. O teatro em museus e centros de ciências no Brasil. História, Ciências, Saúde, Manguinhos, v. 22, p. 1735-1748, dez. 2015.

NORBERTO ROCHA, J. et al. Museus e Centros de Ciências Acessíveis da América Latina e do Caribe. Rio de Janeiro: RedPOP; Montevidéu: Unesco, 2017.

NORBERTO ROCHA, J.; MARANDINO, M. Museus e centros de ciências itinerantes: possibilidades e desafios da divulgação científica. Revista do Encontro de Divulgação de Ciência e Cultura, Campinas, v. 3, n. 3, p. 49-58, abr. 2017.

SALASAR, D. N. Um museu para todos: manual para programa de acessibilidade. Pelotas: UFPel, 2019. 
SARRAF, V. P. Reabilitação do museu: políticas de inclusão cultural por meio da acessibilidade. 2008. 181 f. Dissertação (Mestrado em Cultura e Informação) - Escola de Comunicações e Artes, Universidade de São Paulo, São Paulo, 2008.

SCHUINDT, C. C. A educação inclusiva em espaços não formais: uma análise dos Museus de Ciências brasileiros. 2019. 243 f. Dissertação (Mestrado em Educação em Ciências e em Matemática) - Programa de Pós-graduação em Educação em Ciências e em Matemática, Universidade Federal do Paraná, Paraná, 2019.

TOJAL, A. Política de acessibilidade comunicacional em museus. Museologia \& Interdisciplinaridade, Brasília, v. 4, n. 7, p. 190-202, nov. 2015. 
1 Mestra, Universidade Federal do Paraná (UFPR).

Doutoranda do Programa de Pós-Graduação em Educação em Ciências e em Matemática da Universidade Federal do Paraná (UFPR), Curitiba, Paraná, Brasil. https://orcid. org/0000-0001-5112-2129.

E-mail: claudiaschuindt.cs@gmail.com

2 Doutora, Universidade Estadual Paulista (Unesp). Professora Adjunta do Departamento de Química, do Programa de Pós-Graduação em Educação em Ciências e em Matemática e do Programa de Mestrado Profissional em Química em Rede Nacional da Universidade Federal do Paraná (UFPR), Curitiba, Paraná, Brasil. https//orcid. org/0000-0002-6261-1662. E-mail: camilasilveira@ufpr.br. 